\section{Multidisciplinary SCIENTIFIC JOURNAL OF MARITIME RESEARCH}

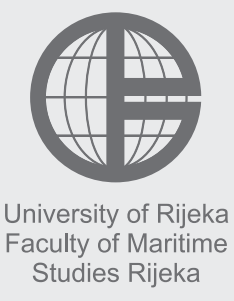

Multidisciplinarni

znanstveni časopis

POMORSTVO

\title{
Small crafts role in maritime traffic and detection by technology integration
}

\author{
Domagoj Komorčec ${ }^{1}$, Dario Matika ${ }^{2}$ \\ ${ }^{1}$ Barbalićeva 1, 52100 Pula, Croatia \\ ${ }^{2}$ Croatian Military Academy “Dr. Franjo Tuđman”, Ilica 256b, 10000 Zagreb, Croatia, e-mail: dario.matika1@gmail.com
}

\section{ABSTRACT}

Maritime traffic has always played an important economic, strategic and transportation role for a maritime country. Small vessels, considering total maritime traffic in the Adriatic Sea, play an important role, although their numbers are often not considered as a potential security risk. Although small vessel accidents do not have damage potential as the large ones, they still need to be regarded as a significant risk to safety of navigation. The first part of this paper shows, thru analysis of SAR action statistical data, that the total number of all accidents is dominated by accidents involving small vessels. A particular problem in the maritime traffic monitoring is the fact that small vessels, because of their characteristics, have a reduced detection probability by modern monitoring technologies and as such can be used as a non-traditional security threat. With development of electronic and information technologies, sensor systems, remote sensing and detection systems, as well as global satellite systems, and the introduction of a legal requirement of AIS on board ships, maritime traffic control has become easier, more organized and more reliable. Although application of these technologies has brought some progress in maritime traffic monitoring, small and fast vessels that are not equipped with AIS system can still be relatively unnoticed in all increasing maritime traffic. For this reason, a solution is perceived in the integration of radar, satellite and electro-optical technologies. The conclusion of this study represents one maritime traffic monitoring possibility that could be a step towards increasing the detection probability of small vessels.

\section{ARTICLE IN FO}

Review article

Received 28 December 2015

Accepted 26 May 2016

\section{Key words:}

Maritime security

Vessel monitoring

Marine radar

Satellite technologies

Electro-optical technologies

\section{Introduction}

Maritime transport on the Adriatic Sea records constant growth each year. Although traffic of ships larger than 300 BT has a major role in a maritime traffic, from the perspective of the Croatian part of the Adriatic Sea, a higher security risk represent small and fast craft in the context of non-traditional security threats. The legal framework for small boats manages to keep that kind of vessels under certain supervision, but in practice such vessels make up the largest share of total accidents in the Adriatic Sea. With the risk of unintentional impact on safety at sea, small boats can also be potentially used as a significant security threats. Small boats size and characteristics make them especially unpleasant for vessel monitoring even with the use of modern technology. Therefore, it is necessary to integrate existing technology with new upcoming technology for the purpose of more qualitative and comprehensive maritime traffic surveillance, control and supervision, with the main aim to prevent maritime accidents and minimize security threats.

The first part of this paper will focus on current situation in maritime traffic and undertaken SAR operations in recent years with special emphasis on small boats. It should be noted that overall situation presented in this paper is applied to Croatia that is to the eastern coast of the Adriatic Sea. Also the paper will discuss non-traditional threats and challenges that they bring in the modern maritime transport. The second part of this paper will deal with the contemporary maritime traffic monitoring systems and their integration for better small vessels monitoring and detection capabilities. Short description of working principle for each technology will be given and also benefits of integration with upcoming technologies will be explained. At the end of the paper a new proposal for improvement of current methods in detecting small boats will be summarized as a result of this research. The focus of this paper will be on small vessels, which although 
are subject to the laws, rules and regulations of international character, yet manage to pass unnoticed by contemporary maritime traffic monitoring system.

\section{Marine traffic and SAR actions in Croatian coast of the Adriatic Sea}

The main maritime routes on the Adriatic Sea are shown in figure 1 (traffic intensity is greater in the area shown in red, while the smaller one in the green or blue), and it is visible that bulk of traffic flows between ports on both sides of the Adriatic Sea [7]. As we can see in figure 1 there is virtually no part on the Adriatic coast without traffic on annual basis.

However, this view is obtained by using data from ships equipped with AIS system (Automatic Identification System). Mandatory use of AIS enabled relatively easy identification of larger vessels, although it should be noted that the AIS system is also susceptible to errors and even hacking threats.

\subsection{Marine traffic - statistical indicators}

It is important to note that a significant portion of traffic is not even shown here due to vast number of small vessels that are not subject to mandatory AIS installation law.

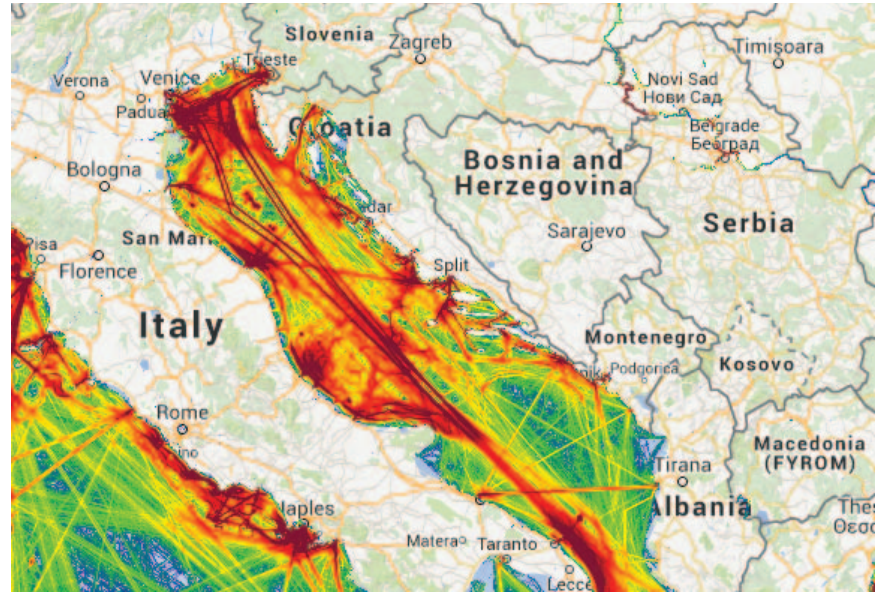

Figure 1 Maritime traffic density on Adriatic Sea, 2014

Source: [16]

Table 1 shows situation in maritime traffic by taking into consideration incoming ships in sea ports in period 2004 2013. Although the share of foreign ships in total turnover varies and is even in the tangible decline in recent years, nevertheless important item is total number of incoming ships which still shows a constant growth trend. Dominant share in the total number of vessels/ships comprise ships under domestic flag.

Table 1 Ports traffic, incoming ships

\begin{tabular}{|l|c|c|c|c|c|c|c|c|}
\hline & \multicolumn{2}{|c|}{ Total } & \multicolumn{2}{c|}{ Domestic flags } & \multicolumn{2}{c|}{ Foreign flags } & \multicolumn{2}{c|}{ International traffic } \\
\cline { 2 - 8 } & \multicolumn{2}{|c|}{ Ships GT '000 } & \multicolumn{2}{c|}{ Ships GT ‘00 } & \multicolumn{2}{c|}{ Ships GT ‘00 } & \multicolumn{2}{c|}{ Ships GT '000 } \\
\hline 2004 & 225212 & 212282 & 219172 & 161583 & 6040 & 50698 & 6112 & 51459 \\
\hline 2005 & 221960 & 233261 & 215671 & 179426 & 6289 & 53834 & 6085 & 55097 \\
\hline 2006 & 223967 & 247560 & 217636 & 192887 & 6331 & 54672 & 6276 & 53885 \\
\hline 2007 & 235489 & 267140 & 229005 & 204118 & 6484 & 63021 & 6579 & 64458 \\
\hline 2008 & 248539 & 286045 & 241184 & 214343 & 7355 & 70702 & 6742 & 70287 \\
\hline 2009 & 247547 & 278948 & 240990 & 210546 & 6557 & 68401 & 6198 & 67834 \\
\hline 2010 & 235841 & 291421 & 229327 & 214753 & 6514 & 76668 & 5691 & 74515 \\
\hline 2011 & 250918 & 296023 & 245266 & 217128 & 5652 & 78895 & 5105 & 76279 \\
\hline 2012 & 247571 & 287782 & 242767 & 210368 & 4804 & 77413 & 4324 & 73473 \\
\hline 2013 & 246939 & 299885 & 242122 & 215476 & 4817 & 84408 & 4072 & 79114 \\
\hline
\end{tabular}

Source: [13, p. 371]

Table 2 Waterway fleet in seawater and coastal transport

\begin{tabular}{|c|c|c|c|c|c|c|c|}
\hline & \multicolumn{3}{|c|}{ Passenger ships } & \multicolumn{4}{c|}{ Cargo ships } \\
\cline { 2 - 8 } & Number & Passenger seats & kW & Number & GT ‘000. & DWT ‘000 & kW ‘000 \\
\hline 2004 & 88 & 30028 & 163710 & 71 & 1320 & 2208 & 418 \\
\hline 2005 & 86 & 31124 & 204182 & 69 & 1353 & 2276 & 422 \\
\hline 2006 & 86 & 31116 & 208299 & 69 & 1425 & 2398 & 447 \\
\hline 2007 & 91 & 34730 & 223878 & 67 & 1502 & 2564 & 448 \\
\hline 2008 & 88 & 34025 & 225324 & 68 & 1586 & 2740 & 466 \\
\hline 2009 & 88 & 34261 & 218437 & 64 & 1561 & 2707 & 449 \\
\hline 2010 & 85 & 33568 & 211065 & 68 & 1631 & 2845 & 458 \\
\hline 2011 & 80 & 32498 & 201297 & 67 & 1656 & 2862 & 491 \\
\hline 2012 & 91 & 32685 & 200539 & 64 & 1612 & 2791 & 482 \\
\hline 2013 & 85 & 32416 & 198477 & 46 & 1225 & 2143 & 371 \\
\hline
\end{tabular}

Source: [13, p. 368] 
Number of ships under domestic flag in table 2 shows that during this ten-year period, number of passenger ships with almost negligible fluctuations has kept approximately the same capacity of passenger seats as well as overall propulsion power. However the number of cargo ships during the same period, with an emphasis on 2013 lost almost $40 \%$ of their previous capacity.

Data shown here represent a clear increase in total maritime traffic in the Adriatic Sea. Data shown here will be complemented by the fact that Croatia has registered 72 floating objects, 4 fixed coastal objects, more than 2500 yachts and 118,000 boats. Also it is worth to mention that in Croatian part of the Adriatic Sea there are around 60,000 foreign recreational vessels each year. For the purposes of this paper we will ignore information relating to other vessel types, so that leaves us with still a big number $(118,000)$ of registered boats in Croatia. Most of these boats sail only in coastal navigation, where maritime transport is very intense especially in summer months, and they definitely need a certain means of surveillance.

\subsection{SAR actions on Croatian coast of the Adriatic Sea in the period $1999-2015$}

Total number of ships in a specific time period that arrives to the Adriatic Sea ports is visible from previous table. Presented numbers are by no means negligible, and also do not give the full scope of traffic situation in the Adriatic Sea. In order to have clear situation about total maritime traffic we have to take into account ships in transit only as well as small boats that are not included in the annual statistics, even though they play a major role in overall traffic. We do not have official data for total number of small vessels in annual maritime traffic, but we can assume that by taking into account overall traffic a total count multiplies significantly. Although we are deal- ing with really large quantity of ships and boats, number itself is not as important as a fact that the consequence of such intense traffic is increased possibility of unfortunate events.

We will again highlight the importance that maritime traffic surveillance and monitoring has for prevention of unfortunate events at sea. Although statistics for all undertaken SAR actions in Croatian coast of the Adriatic Sea are presented here, we will try to focus on small vessels and their representation in total number of undertaken actions.

Data presented in table 3 apply to total number of actions taken for each year in the period. Types of action from this data are not related to ships size, but are rather described through the characteristics of individual SAR action. We will filter obtained data to extract data which will provide insight on the impact of small vessels (mentioned here as the boats) on the overall situation in SAR actions. From 2011 official statistics for undertaken SAR action started to distinguish types of vessels as ships, boats and other crafts. As we can notice in figure 2, small boats are the most represented in total undertaken SAR actions.

If we compare the numbers from figure 2 , relating to total number of SAR actions and rescued vessels, it is evident that the largest number of SAR actions refers just to small boats. The aforementioned number of registered boats in Croatia (even though they are not all equally active during year), needs to be increased for foreign boats that operate during the summer months. From total number of boats in the Adriatic Sea, the number of boats that participate as subjects of accident in SAR actions, in reality is not too large. Simple calculations show that it is possible to conclude that considering the number of vessels, the number of search and rescue actions is identical to the number of vessels. However, here we should be careful because the table 4 shows "only" rescued vessels

Table 3 Statistical indicators for SAR actions in the period 2008 - 2014

\begin{tabular}{|c|c|c|c|c|c|c|c|}
\hline Cause of action & 2008 & 2009 & 2010 & 2011 & 2012 & 2013 & 2014 \\
\hline Grounding & 32 & 59 & 43 & 59 & 51 & 42 & 60 \\
\hline Reduced maneuvering ability & 81 & 88 & 105 & 85 & 78 & 60 & 59 \\
\hline Medical intervention & 70 & 42 & 45 & 50 & 59 & 38 & 33 \\
\hline Sinking & 6 & & 20 & 15 & 10 & 17 & 11 \\
\hline Man over board & 9 & 9 & 14 & 15 & 12 & 5 & 6 \\
\hline Collision & 2 & 3 & 9 & 15 & 12 & 8 & 15 \\
\hline Other (red rocket, assistance...) & 37 & 25 & 90 & 34 & 71 & 79 & 44 \\
\hline Fire & 8 & 8 & 8 & 9 & 7 & 12 & 8 \\
\hline Inclination/capsize & 8 & 16 & $*$ & $*$ & $*$ & $*$ & 7 \\
\hline Rescued crafts** & 137 & 200 & 179 & $21 / 183 / 22$ & $12 / 143 / 12$ & $9 / 117 / 19$ & $8 / 198 / 9$ \\
\hline Rescued persons & 585 & 957 & 944 & 876 & 825 & 646 & 774 \\
\hline
\end{tabular}

Source: [11]

Note:* data not available; ${ }^{* *}$ from 2011 data published separately for ships/small vessels (boats)/other crafts 


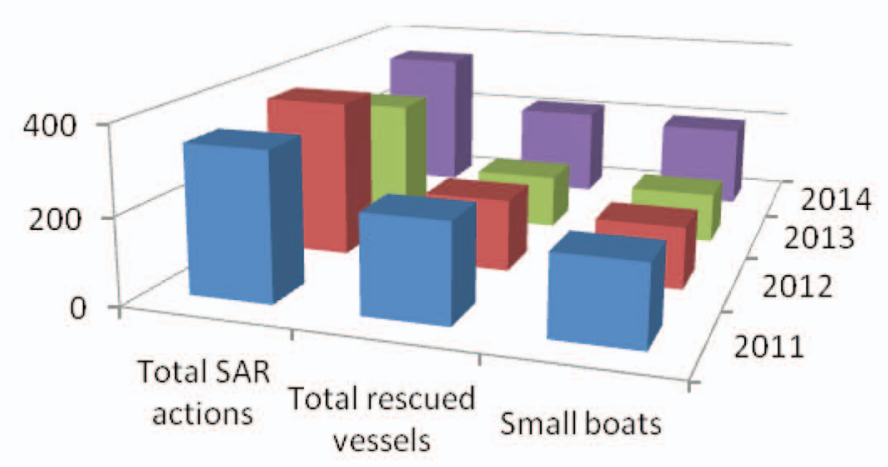

Figure 2 SAR actions and total number of rescued vessel-ratio in the period $2011-2014$

Source: [11]

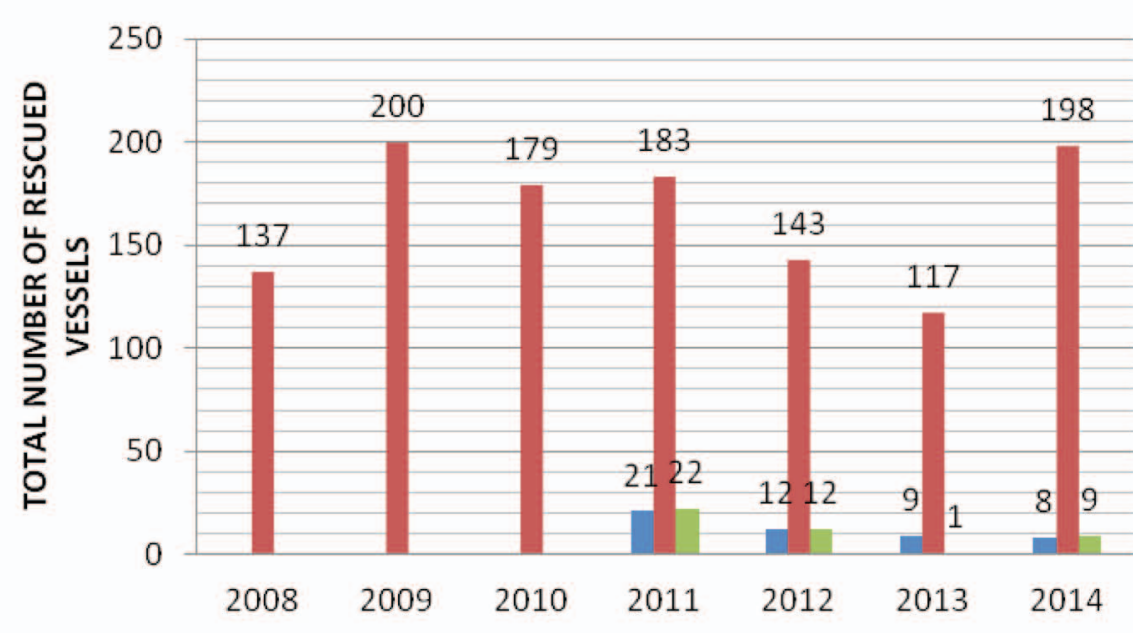

Ships

Small boats

Other crafts

Chart 1 Rescued vessels in SAR actions in the period 2011 - 2014

Source: [11]

Table 4 Characteristics of radar targets for X band radar

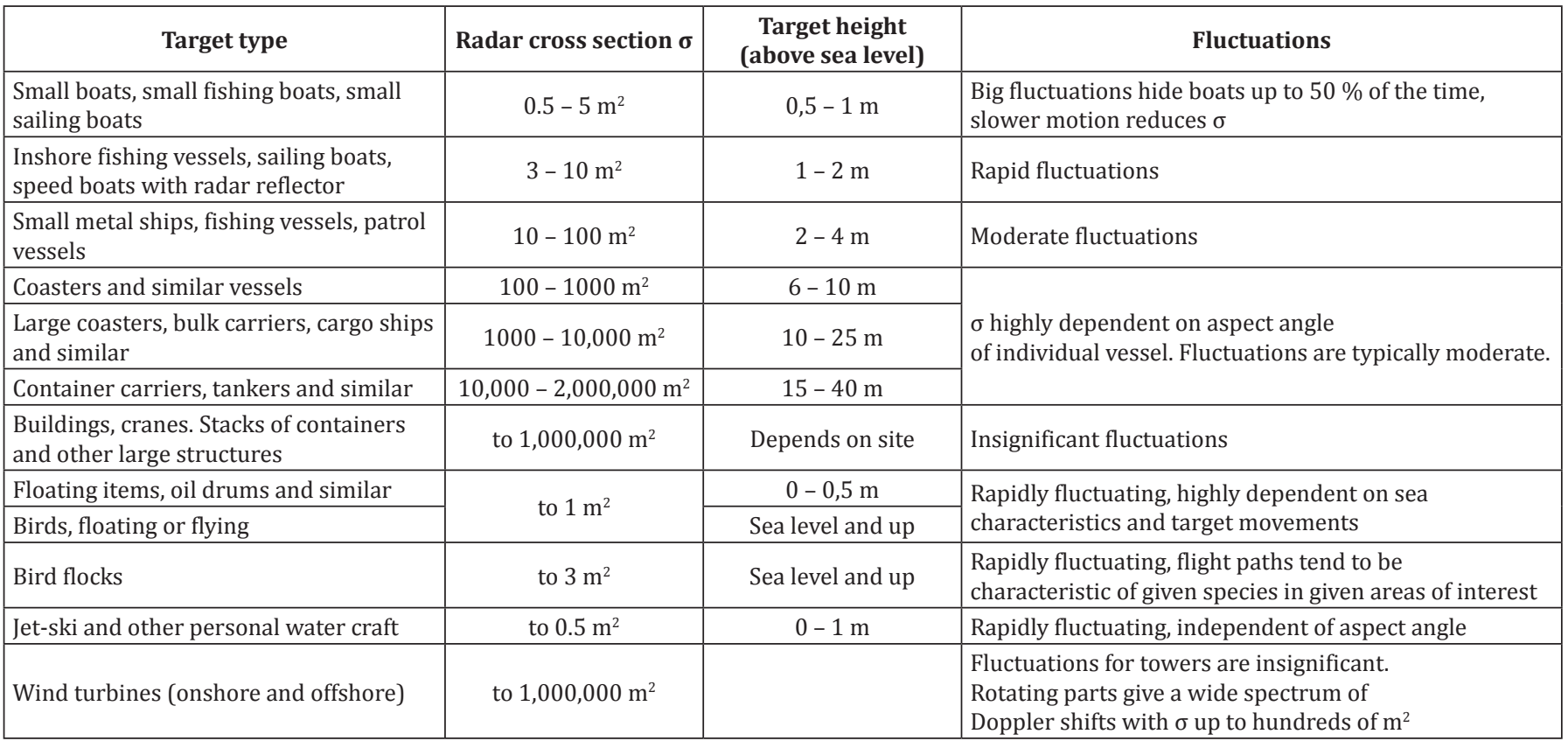

Source: [6] 
which leaves room for a mistake, if we do not take into account number of vessels that are not rescued or have sunk. From presented data, we cannot determine with certainty the exact number of vessels in relation to the number of SAR actions because it can also happen that in one SAR action two or more boats participated as victims.

Goal of the surveillance and monitoring of maritime traffic is certainly the introduction of a particular order in daily maritime traffic, which has the effect of reducing number of maritime accidents, primarily saving human life, as well as vessels and cargo preservation and protection. Preservation of the marine environment and prevention of coastline pollution is also very important factor for improvement of current monitoring methods. Another important aim of maritime traffic surveillance is to prevent the occurrence of illegal acts that could potentially turn into a security threat.

\subsection{Types of non-traditional threats and small boats}

In order to understand the significance of the impact of non-traditional security threats in the modern maritime traffic we need to clarify the basic concepts related to the aforementioned threats. In the context of non-traditional security threats we will mention only the most significant ones, even though all types of threats are not equally presented in the Adriatic Sea. Types of non-traditional maritime threats can be divided as: human trafficking, modern piracy, maritime terrorism, organized crime at sea (trafficking of drugs, people, illegal weapons, etc.), climate change, fish stock reduction and so on. Threats listed here should be viewed in the context of the potential impact they have on possible casualties, a significant property damage, environment pollution, safety of navigation, etc.

Small boats can be considered, according to most authors, vessels with length of less than $20 \mathrm{~m}$. When we are talking about the small vessels in this paper we shall consider them as vessels up to $20 \mathrm{~m}$ in length. Although shape and structure of such vessels could be different; with cabin, with no cabin, boat, fishing boat, etc, a common characteristic of all these vessels are small dimensions, which makes them especially difficult to detect in the modern maritime traffic monitoring systems. Sometimes small dimensions of the vessels are often combined with high speed which in combination with unfavorable weather conditions makes them extremely difficult to detect and track.

\section{Small boats monitoring methods in the maritime traffic}

Growing volume of maritime traffic, coupled with the constant increase in the number of vessels assumes existence of particular means of monitoring and surveillance of traffic at sea. Thanks to development and implementation of new technologies, maritime traffic monitoring methods were raised to a higher level.

\subsection{Radar systems and small crafts detection problems}

In maritime traffic monitoring radar is used as a mean of detecting targets at sea. Given that a receiving reflected signal (Signal, S) used for target detection depends on level of noise (Noise, $N$ ) on the same frequency, radar will detect target within its range if the return signal from target is larger than the signal of interference and if the radar system it is for this $S / N$ ratio sensitive enough [3, p. 48]. For the $S / N$ ratio is valid:

$$
S / N=D T ; D T=10 \log (S / N)[\mathrm{dB}]
$$

where we have:

$D T=$ detection threshold

$S / N=$ signal to noise ratio

It is valid that for $\mathrm{DT}=0 \mathrm{~dB}$ longest detection range $R=R_{\max }$ will be acquired. Received signal power density Scan be expressed by [3, pp. 51-52]:

$$
S=\frac{P_{t} G_{t}^{2} \sigma \lambda^{2}}{(4 \pi)^{3} R^{4}}[\mathrm{~dB} / \mathrm{W}]
$$

where parameters are defined as:

$P_{t}=$ peak radar power at antenna [W]

$G_{t}=G_{r}=$ antenna gain $[\mathrm{dB}]$

$R=$ range $[\mathrm{m}]$

$\sigma=$ radar cross section $\left[\mathrm{m}^{2}\right]$

$\lambda=$ wavelength $[\mathrm{m}]$

After logarithmic operation of equation (2) due to $\mathrm{dB}$ conversion, equation now has a form as:

$$
S=S L+2 D I_{t}-2 T L+T S
$$

with parameters as follows:

$S L=$ source level which is $P_{t}$

$D I=$ directivity index which is $G_{t}$ and $G_{r}$

$T L=$ transmission loss

$T S=$ target strength which is $\sigma$

Total noise density $N$ depends on antenna noise temperature i.e., total receiver input noise $N L_{a}$ at standard temperature $T_{A}=290{ }^{\circ} \mathrm{K}$ will be expressed as [3, p. 58]:

$$
N L_{a}=10 \log \mathrm{k} T_{A} B_{n} F_{n}[\mathrm{dBm}]
$$

where we have:

$\mathrm{k}=$ Boltzmann constant $\left[\mathrm{J} /{ }^{\circ} \mathrm{K}\right]$

$T_{A}=$ antenna temperature $\left[{ }^{\circ} \mathrm{K}\right]$

$B_{n}=$ noise bandwidth $[\mathrm{Hz}]$

$F_{n}=$ noise factor

From aforementioned equations $D T$ can be defined as:

$$
(S / N) 0=S(d B m)-N L_{a}(d B m)=D T=S N R_{\text {min }}
$$

Radar equation can be further developed through (2), (4) and (5) respectively also with parameter $R_{f s p}$ which expresses radar free space propagation range as:

$$
R_{f s p}=\left\{\frac{P_{\mathrm{t}} G_{\mathrm{t}}^{2} \sigma \lambda^{2}}{\left[\mathrm{k} T_{\mathrm{A}}(4 \pi)^{3} B_{\mathrm{n}} F_{\mathrm{n}} S N R_{\text {min }}\right]}\right\}^{\frac{1}{4}}[\mathrm{~m}]
$$


If we introduce radar factor $F_{r}$ in radar equation and perform conversion in nautical miles for maritime radar purposes, radar equation gains its final form as:

$$
R_{f s p}=\left[\frac{\mathrm{k}_{\mathrm{NM}} F_{\mathrm{R}} \sigma \lambda^{2}}{S N R_{\min }}\right]^{\frac{1}{4}}[\mathrm{NM}]
$$

where:

$R_{f s p}=$ radar free space propagation range [NM]

$\mathrm{k}_{\mathrm{NM}}=1 /[(4 \pi) 3 \cdot 18,524]=5.72 \cdot 10^{-17}-$ nautical mile conversion coefficient

$F_{\mathrm{R}}=$ radar factor

$\sigma=$ radar cross section $\left[\mathrm{m}^{2}\right]$

$\lambda=$ wavelength at $\mathrm{X}$ and $\mathrm{S}$ frequency band $[\mathrm{m}]$

$S N R_{\text {min }}=$ detection threshold, signal to noise ratio - at which reliable target detection occurs.

Previous formula indicates a range of maritime radar and parameters that have an impact on this range. Except for the distance from the transmitter, target detection also depends on the surface of radar cross section $\sigma$. We can say that successful target detection depends on following physical properties of vessels: target height above sea surface, size and shape of target, radar cross section and speed of moving target. Since X band radar is primary detection system used in maritime traffic table 3 shows characteristics of target regarding radar cross sections and target height above sea level.

Commercial vessels represented in maritime transport are not built with the purpose of hiding them from radar detection. Still, small boats despite their relatively small probability of detection in certain conditions at sea, can pose a security threat, especially if masking techniques for decreasing radar cross section are used.

\subsection{Electro - optical systems and small crafts detection problems}

Application of electro-optical (EOS) technology is another important aspect of modern maritime traffic supervision and monitoring, which is especially important for monitoring of ships entering the port, in narrow channels and river waterways. Optical technology in marine environment in context of surveillance and maritime traffic monitoring is mostly used through CCTV systems, infrared and laser camera application for day and night observation. EOS technology can be a primary or secondary source for maritime traffic monitoring, whose priority will be determined by the area in which it is applied, integration with other monitoring technology, traffic density in a certain area, etc. Complexity of applied EOS technology may vary depending on options that may be implemented that is, it may serve as a support for simple video recording of a specified area or to performing complex analysis of captured images, creating prerequisites for reliable decision-making. However, in order to successfully meet the modern requirements for surveillance and monitoring of maritime traffic, EOS systems must be able to detect an object at sea, then to recognize it according to algorithm, classify vessel (specify the type of the ship -ferry, tanker, RO-RO, etc.) and finally, to identify it by name or MMSI number.

Appearance of observed objects depends on parameters such as: distance, lighting or color, viewing angle, and shape and size of the object. Each of these parameters is subject to change in real time. To be able to detect and identify the object on the video image it is necessary to apply certain video image (figure 3) analyzing and processing methods [15]. Given the complexity of the processing and analysis of video images we will not go into the details of the process itself but rather we will only briefly enumerate certain methods that are used within EOS systems. Manipulation methods for video images in EOS technology are divided according to properties, processing, and general characteristics; here we will list just a few of the most important:

- Edge detection - as in each image there is a discontinuity or difference of pixel illumination, it is possible to outline boundaries of certain objects at the edges of these differences in light intensity, and in this way to determine the edges of the object on image. In this way it is possible to isolate object which we want to analyze and reduce the processing of entire image on only one image part which in turn reduces the amount of data needed for processing.

- Blob detection - idea behind this approach consists in the fact that there are areas on image that have common properties (for example, color, intensity, etc.) which is different in relation to the environment in which they are located. These areas are further processed and can be used to detect presence of objects on image.

- Pattern recognition - this method compares a specified object from video image in different perspectives, the intensity of the brightness, contrast, etc. with the currently available image. A prerequisite for a successful detection of object in image is a data base as large as possible of the same object with different characteristics.

- Optical flow - by measuring the flow rate of object between individual frames you estimated the speed of the object on image. Here is valid that shapes that move at a certain speed closer to the camera show a greater amount of motion in relation to the objects away from the cameras, even though both are moving at the same speed.

When using EOS technologies special attention needs to be observed for necessary infrastructure for transfer of large quantities of data. In the context of the small vessels the EOS technology has a particular advantage in front of radar technology, especially when it comes to the supervision of the restricted areas, such as ports, channels, or waterways. If we want to devise a more advanced system of supervision and monitoring of maritime traffic, which apart from the traffic monitoring will be able to do a specific analysis and processing of captured images it is necessary to implement high definition EOS system as seen in 


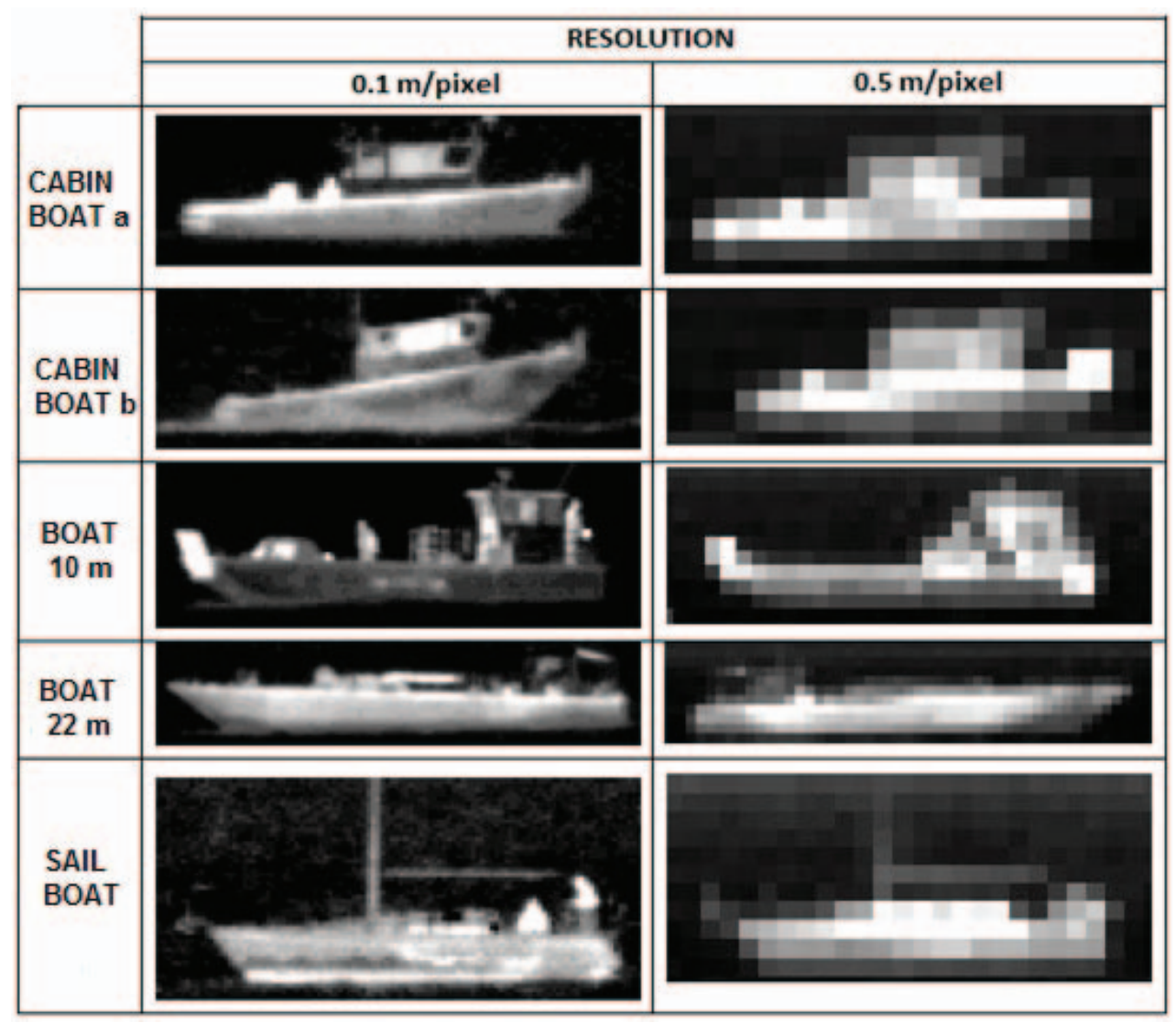

Figure 3 Vessel in IR image - high and low resolution

Source: [15]

figure 3. A major role in larger area monitoring plays camera resolution, however the development of the EOS technologies and improvement of the resolution of the camera in the near future will allow covering vast maritime areas.

\subsection{Satellite technology - technology integration}

Step towards the improvement of maritime traffic supervision and monitoring is manifested through use of satellite technology, in particular SAR (Synthetic Aperture Radar) technology. It is radar technology, situated on orbital satellite that is constantly circling the Earth at an altitude of 700 to $800 \mathrm{~km}$. Operation principle of radar is no different than classical radar where electromagnetic pulses are transmitted by $300 \mathrm{GHz}$ up to $300 \mathrm{MHz}$ frequency and strength of reflected signal is measured as seen on figure 4. Essential difference compared to classic radar is in context of radar image processing, which, in this case may be a 2 or 3-dimensional thus giving a clearer insight into current situation on the sea. Advantage of SAR radar is emphasized in fact that a radar signal is not dependent on weather conditions or direct sunlight and is suitable for use in almost all meteorological conditions. Application of this system is associated with a project of the European Agency for the protection of the sea EMSA, which wanted to strengthen the surveillance over the sea with goal to prevent oil spilling.

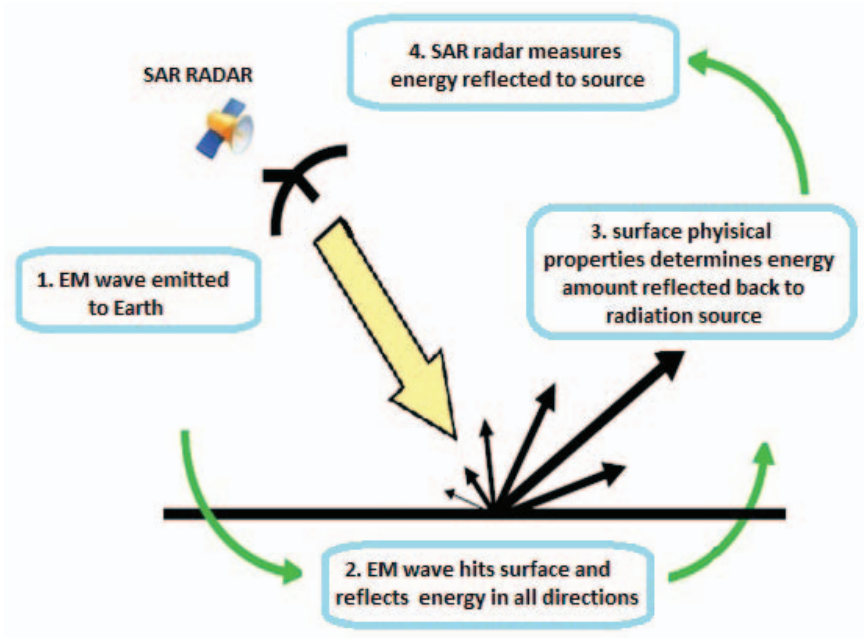

Figure 4 SAR radar operating principle

Source: $[2]$

The satellite technology i.e. SAR radar technology has existed for a number of years, however, its use in maritime traffic surveillance and monitoring has just began in the past few years $[9,10]$. As a relatively new system for use in surveillance and monitoring of ships, this technology has its drawbacks, as it cannot determine azimuth of object, inability to deliver actual data about the objects 


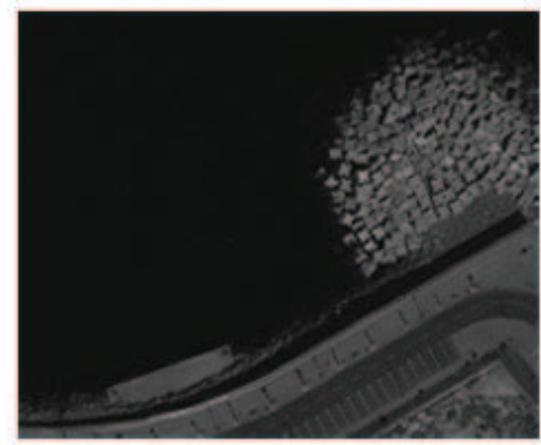

SHORE

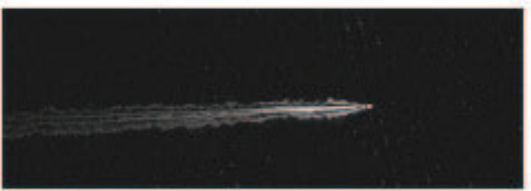

SPEEDBOAT WITH WAKE

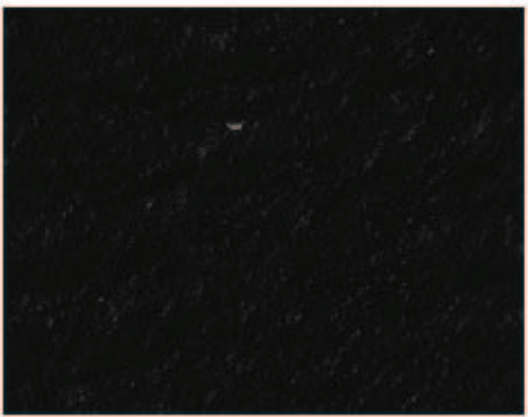

WAVES

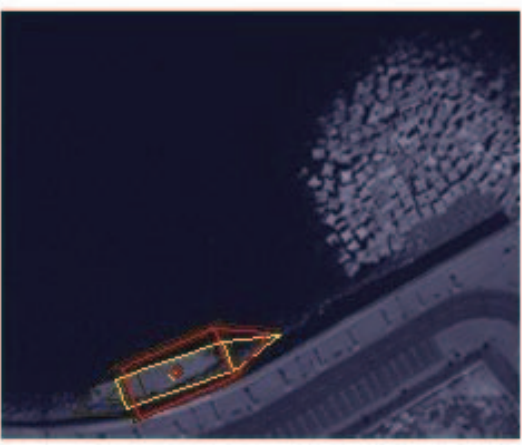

FALSE DETECTION NEAR SHORE

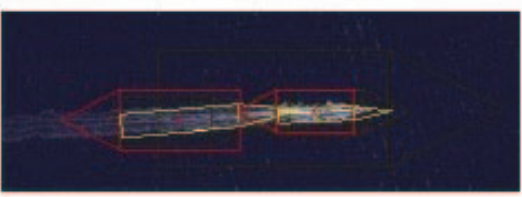

DETECTIONS ON SPEEDBOAT WAKE

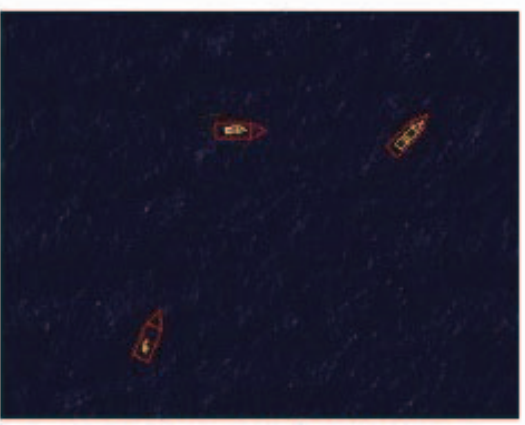

FALSE DETECTION ON WAVES

Figure 5 Typical errors in SAR radar technology detection

Source: [9]

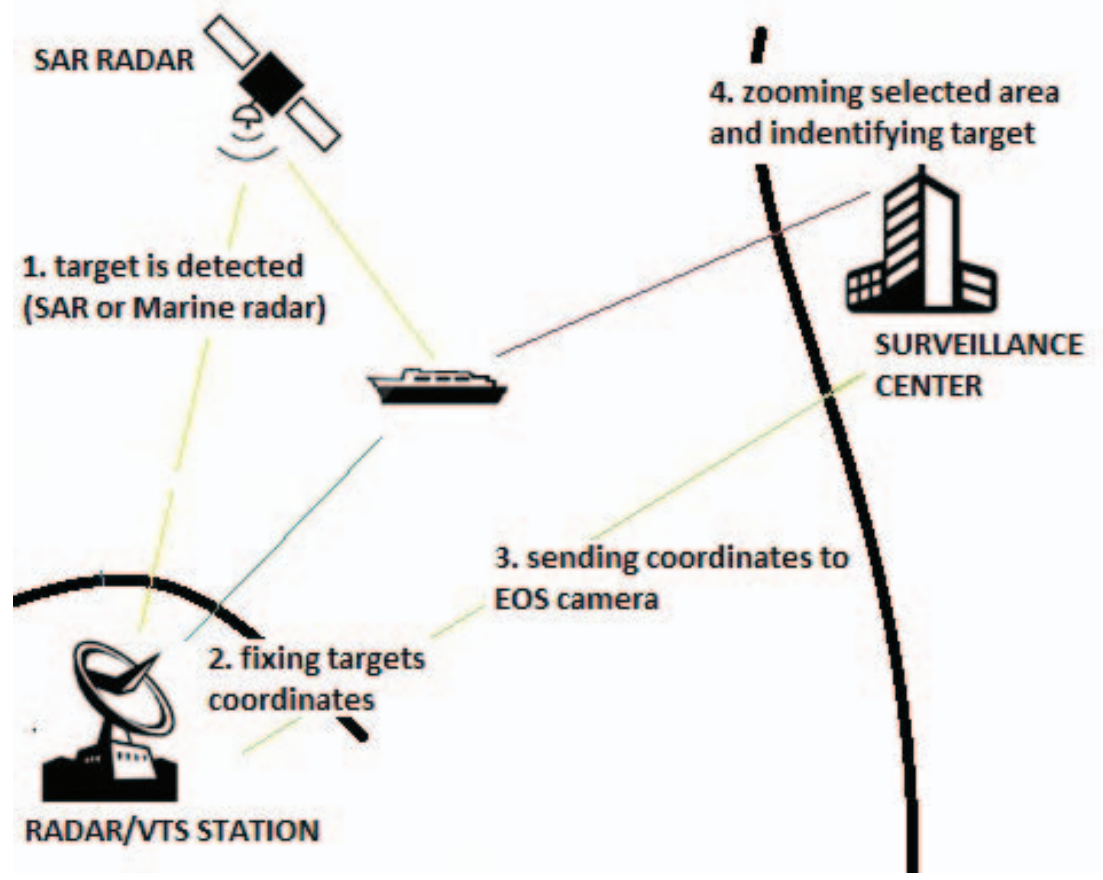

Figure 6 Technology integration for detecting low visibility targets 
shape in most situations, impossibility of identifying vessels that are smaller than $15 \mathrm{~m}$. The biggest disadvantage of this technology is still inadequate detection probability of smaller vessels as well as errors that occur in the form of false detections arising due to disturbances at observed image, as seen of figure 5 .

Integration of satellite-based radar technology with the AIS system, classic radar system or EOS technology can improve mentioned deficiencies. Regardless of aforementioned shortcomings, this technology will find its application in future maritime traffic monitoring and surveillance systems.

\subsection{Technology integration as a mean for small crafts detection}

By reviewing existing technologies it is evident that each of these technologies has certain advantages and disadvantages. Also the probability of detecting small vessels with these technologies varies according to external parameters, such as weather conditions, sea state, density of traffic, distance of the object, shape of the object and others. The logical solution to improve maritime traffic monitoring and safety of navigation is in integration of existing technologies in functional unit.

One such example of technology integration will be displayed here in figure 6. We will assume that the vessel in example is not equipped with the AIS system and it could not be immediately identified, also a vessel is located in the range zone of radar signal.

In one monitored area surveillance is done primarily with X band radar system and backed up with SAR system. Each of these systems has a range greater than the EOS system and that range in turn depends on external factors. At a certain point the radar detects the object which still is not detectable for the camera. Radar determines the azimuth and distance of an object and therefore it is possible to track position of detected object. VTS System calculates objects position as geographical coordinates $(\lambda$ and $\varphi$ ), making it possible to be forwarded to the EOS System.

The secondary surveillance system is EOS surveillance camera that has a fixed position and the possibility of detecting the movement of the target in the video image. When a particular camera resolution is set, for this resolution all geographical coordinates in the supervised area are well known. The EOS system and X band radar are interconnected and based on the coordinates that VTS sends to the camera, camera zooms area and detects target providing a more detailed image of object allowing reliable identification.

\section{Conclusion}

Small boats traffic presents significant share of total maritime traffic in the Adriatic Sea. Also the biggest part of all undertaken SAR actions are small boats rescue operations and as shown this is a big problem that poses a significant threat to the maritime traffic safety on Croatian coast of the Adriatic Sea. Although in last few years there was seen development of AIS system, VTS service for control and monitoring of maritime traffic, EOS and radar surveillance technology introduction, the problem of monitoring and surveillance of small boats traffic is not completely solved. Proposal shown in this paper is concerned with technology integration which is still to be developed and put to practical solution. Most improvements are expected to be developed in EOS systems which will be integral part of many future vessel monitoring solutions. To determine the actual usefulness of this kind of technology integration and calculate increase of object detection probability at sea it is necessary to conduct further research, especially in EOS applications. This paper has proposed concept for further development of maritime monitoring system and can be regarded as one step closer in achieving that goal.

\section{References}

[1] ADRIA VTS Report v2.1.2009.

[2] EMSA SAR image analysis CleanSeaNet training material.

[3] Gržan M.: "Selektivno ometanje radarskih sustava i utjecaj na sigurnost plovidbe u uvjetima suvremene ugroze", doctoral dissertation, Rijeka, 2012.

[4] Gržan M., Nekić D., Ostović Lj.: "Poboljšanje sustava nadzora morskog ribarstva u plinskom eksploatacijskom polju Sjeverni Jadran", Pomorstvo 27/1 2013, pp. 157-177.

[5] Gržan M.: "Procedures and Deck Officer Training in Cases of Intentional Radar System Jamming and Deception", Naše more 61(3-4)/2014, pp. 67-76.

[6] IALA Guideline No. 1111 on Preparation of Operational and Technical Performance Requirements for VTS Systems; Edition 1, 2015.

[7] Lušić Z., Pušić D., Galić S.: "Pomorski promet i nezgode na hrvatskom dijelu Jadrana", 3. International Conference on Maritime Science, Split, MSC, 2011.

[8] Matika D., Gržan M.: "Optimizing Marine Radar Performance in Enhancing the Safety of Navigation", 2013.

[9] Mattyus G.: "Near Real-Time Automatic Marine Vessel Detection on Optical Satellite Images", International Archives of the Photogrammetry, Remote Sensing and Spatial Information Sciences, Vol. XL-1/W1, ISPRS Hannover Workshop, 2013.

[10] Marshburn E. G., Wang Y., Allen T. R.: "Potentials and Impediments for Operational Remote Sensing of Small Recreational Vessels", ASPRS Conference, Baltimore, Maryland, 2009.

[11] Statistical Data for SAR Actions in the Period 2008 - 2014, MRCC Rijeka.

[12] Statistical Yearbook of the Republic of Croatia, 2013.

[13] Statistical Yearbook of the Republic of Croatia, 2014.

[14] Strategija pomorskog razvitka i integralne pomorske politike Republike Hrvatske za razdoblje od 2014. do 2020. godine, Zagreb, 2013.

[15] Van den Broek S., Bouma H., Den Hollander R., Veerman H., Benoist K., Schwering P.: "Ship Recognition for Improved Persistent Tracking with Descriptor Localization and Compact Representations", Proc. SPIE, Vol. 9249, 2014.

[16] www.marinetraffic.com 